\title{
Mechanical and Biochemical Methods for Rigor Measurement: Relationship with Eating Quality
}

\author{
Carlos Álvarez (D), ${ }^{1}$ Lara Morán ${ }^{(D)},{ }^{2}$ Derek F. Keenan, ${ }^{1,3}$ Anne-Maria Mullen (D), \\ and Gonzalo Delgado-Pando $\mathbb{D}^{1}$ \\ ${ }^{1}$ Department of Food Quality and Sensory Science, Teagasc, Food Research Centre Ashtown, Dublin 15, Ireland \\ ${ }^{2}$ Lactiker Research Group, Department of Pharmacy and Food Science, University of the Basque Country (UPV/EHU), \\ Álava 01006, Vitoria, Spain \\ ${ }^{3}$ Pesticides Control Service, Department of Agriculture, Food and the Marine, Backweston Laboratory Complex, Young's Cross, \\ Celbridge, Kildare, Ireland \\ Correspondence should be addressed to Gonzalo Delgado-Pando; g.delgado.pando@gmail.com
}

Received 22 February 2019; Accepted 26 May 2019; Published 13 June 2019

Academic Editor: Jordi Rovira

Copyright ( 2019 Carlos Álvarez et al. This is an open access article distributed under the Creative Commons Attribution License, which permits unrestricted use, distribution, and reproduction in any medium, provided the original work is properly cited.

\begin{abstract}
Meat quality parameters are affected by a complex series of interacting chemical, biochemical, physical, and physiological components that determine not only the suitability for consumption and the conditions for further processing and storage but also consumer acceptability. Deep understanding and careful manipulation of these intrinsic and extrinsic factors have to be taken in account to ensure high quality of meat, with better technological properties and increased safety for consumers. Among meat quality characteristics, meat tenderness has been perceived as the most important factor governing consumer acceptability. Therefore, being able to early predict meat texture and other related parameters in order to guarantee consistent eating quality to the final consumer is one of the most sought-after goals in the meat industry. Accurate measurements of both the biochemical and mechanical characteristics that underpin muscle and its transformation into meat are key factors to an improved understanding of meat quality, but also this early-stage measurements may be useful to develop methods to predict final meat texture. It is the goal of this review to present the available research literature on the historical and contemporary analyses that could be applied in early postmortem stages (pre-rigor and rigor) to determine the biochemical and physical characteristics of the meat that can potentially impact the eating quality.
\end{abstract}

\section{Introduction}

Since the 1970s, there has been an academic interest in the management of meat quality with the goal of reducing the inherent variability of the product at retail [1-3]. Consumer perspectives on meat quality are complex, and meat quality is a continuously evolving concept [4]; however, for decades, meat tenderness has been perceived as the most important factor governing consumer acceptability [5], although there is a growing acceptance that other factors, specially flavour, have greater influence than initially thought $[6,7]$. More recently, other factors are known to play a role in this arena, such as sustainability [8], animal welfare $[9,10]$, or healthy lifestyle [11].
Despite breakthrough research and the implementation of the findings to the management of meat quality, surveys from 2017 indicated that considerable variation in the tenderness of beef cuts was still present and the same range of variation was found than in the previous surveys carried out in the past 15 years [12-16]. Reducing this variation is paramount in order to win consumers' confidence [6]. Meat quality in general, particularly textural characteristics, has become so important for the consumers that several countries have included a quality classification in their grading systems: Australia, Canada, Japan, and USA [17]. The quality assessment is usually done on the ribeye by means of marbling determination, but the Australian system (Meat Standard Australia) has also included a cook $x$ cut 
based model, taking into account the consumer perception on tenderness, juiciness, flavour liking, and overall liking [18].

There are many pre- and postslaughter factors affecting eating quality attributes of meat. Intrinsic preslaughter factors include genetics, breed, gender, type of muscle, and age of the animal, while the extrinsic encompasses nutrition/ dietary management, animal health, animal welfare, stress management, and climate [19-21]. Postslaughter extrinsic factors include slaughter protocol, postslaughter interventions (e.g., temperature control, electrical stimulation, hanging method, or ageing), storage, conservation and display (e.g., packaging), and cooking time/type [22$24]$,which are some of the main factors.

In this regard, after slaughtering, the most important processes affecting the development of meat texture begin when the blood irrigation stops, triggering the development of the conversion process from muscle to meat [20]. This process has been divided into three main stages: (a) pre-rigor phase; (b) rigor phase; and (c) tenderisation phase (proteolysis by enzymes, such as calpains and cathepsins) [25]; however, the contribution of a fourth step (apoptosis, taking place before the rigor step) has been proposed by Ouali [26].

Briefly, during the pre-rigor and rigor phases, several changes occur within the muscle. Firstly, a depletion of the total available energy takes place in muscle, followed by a shift from aerobic to anaerobic metabolism, which, in turn, leads to the production of lactic acid. Subsequently, there is a rise in the ionic strength of the muscle, due, in part, to the lack of adenosine triphosphate (ATP) which prevents the work of the ion ATP-dependent pumps (calcium, sodium, and potassium) [27]. Finally, the cell is not able to maintain reducing conditions and calcium pumps stop working, inactivating the relaxation capacity of the muscle and establishing rigor mortis [28]. Regarding the tenderisation phase, two main theories have been proposed to explain the changes observed in meat structure and tenderness. The most widely accepted theory is based on the presence of endogenous calcium-activated proteinases (such as calpain and its regulator calpastatin, and cathepsins) which are able to hydrolyse the myofibrillar proteins, giving as result a loss of structure and further tenderisation [29]. To date, the proposed mechanisms of proteolysis have been comprehensively reviewed by others [29-31]. The other theory suggests that the accumulation of calcium ions in the sarcoplasm-due to the lack of activity of ATP-dependent pumps-increases the ionic strength, leading to a solubilisation of the myofibrillar structural elements which will be further degraded [32]. However, none of the theories is currently fully supported by empiric evidence. In any case, it seems clear that proteolysis is, at least in part, one of the main players for postmortem tenderisation. Recent research has demonstrated that degradation of structural proteins such as desmin, nebulin, or titin (which are the substrates of calpains) is highly correlated with the final tenderness $[33,34]$. Finally, the role of apoptotic routes has been recently highlighted [35]. Briefly, apoptotic factors such as cytochrome $\mathrm{C}$ when overexpressed promote calpain activity, thus improving tenderisation on the aging phase. On the other hand, heat shock proteins (HSP) related to stress have been found to inhibit calpain activity when overexpressed, leading to lesser degree of tenderisation.

In order to measure the meat tenderness of the final cut, several methods have been developed. The most common include both objective (TPA and shear force) and subjective (sensory panel) measurements. However, an early prediction of eating quality during the pre-rigor and rigor phase will have a clear impact on processing, research, and production. In this regard, the present paper wishes to review the methods that have been employed or can be employed during the pre-rigor and rigor phase to evaluate meat characteristics and how they relate to the final meat eating quality, with main focus on textural parameters. We assessed how these methods could be potentiality used as early meat quality/tenderness markers.

These methods can be grouped into biochemical methods, which aim to determine the concentration and activity of molecules and enzymes involved in the glycolysis process during rigor mortis; physical/mechanical methods measuring the textural and mechanical properties of the muscle during this early stage; and finally, rapid nondestructive techniques performed online usually based on image analysis or spectroscopy.

\section{Muscle Metabolism, Postmortem Glycolysis, and Meat Quality}

In order to fully understand the principles and mechanisms underpinning these methods, it is important to review the biochemical processes at play in the early postmortem stage and the subsequent rigor mortis onset.

Despite the fact that carbohydrates make up a relatively small percentage of muscle tissue $(0.5-1.5 \%$ of total muscle weight [36]), they play a major role in the process of transforming muscle into meat $[37,38]$. Glucose and glycogen are the preferred molecules employed in muscle metabolism and can be both used in either an aerobic (oxidative phosphorylation) or an anaerobic (anaerobic glycolysis) environment [39]. By far, the most important one of the two energy sources is glycogen as its preslaughter concentration ( $500 \mathrm{mmol} / \mathrm{kg}$ dry muscle) is related with $\mathrm{pH}$ decline during anaerobic metabolism (due to the accumulation of lactic acid during the transformation of glycogen to ATP). It has been reported that about $45 \mathrm{mmol}$ of glycogen is needed to lower the $\mathrm{pH}$ of $1 \mathrm{~kg}$ of muscle from 7.2 to 5.5 [40]. This value is quite constant, and this process stops when the $\mathrm{pH}$ of meat is 5.6 to 5.3 [40], due to the inactivation of involved enzymes; therefore, when the amount of residual glycogen after $\mathrm{pH} 5.5$ has been reached, it can be used to determine the preslaughter glycogen concentration [41].

Glycogen can be found in two forms: (1) as proglycogen (PG), which is smaller (up to $400 \mathrm{kDa}$ ) and not soluble in perchloric acid $\left(\mathrm{HClO}_{4}\right)$ and (2) as macroglycogen $(\mathrm{MG})$, which is larger (approx. $107 \mathrm{kDa}$ ) and is $\mathrm{HClO}_{4}$-soluble [42] The PG degradation rate is higher at normal or high glycogen levels compared to MG [43]. Other sources of energy are phosphocreatine, lactate, fatty acids, and triglycerides. However, lipids and lactate can be employed as source of 
energy only under aerobic conditions. In the case of lipids, the efficiency of adenosine triphosphate (ATP) generation is very high, but the rate of conversion into ATP is twice as slow as compared to ATP synthesis from glycogen in aerobic conditions (1.5 vs $3 \mathrm{mmol} / \mathrm{kg} \cdot \mathrm{s}$, respectively) [44]. When glycogen is used in anaerobic conditions, the conversion rate increases up to $5 \mathrm{mmol} / \mathrm{kg} \cdot \mathrm{s}$ [44].

The glycogen content of animals at rest, or just after slaughter, has mostly been estimated by the glycolytic potential (GP). The GP is defined as the ability of the muscle to generate postmortem energy and can be determined by measuring the content of glycogen, glucose, glucose-6-P, and lactate expressed as lactate equivalents as follows [45]:

$$
\begin{aligned}
{[\mathrm{GP}]=} & {[\text { lactate }]+2(\text { [glycogen }] } \\
& +[\text { glycogen }-6-\mathrm{P}]+[\text { glycogen }]) .
\end{aligned}
$$

During muscle function in vivo, myoglobin is responsible for oxygen transportation within the muscle cell. However, the oxygen supply ceases after slaughter and the remaining oxygen is rapidly consumed, resulting in extreme hypoxia conditions. The lack of oxygen activates the anaerobic pathways. Immediately after the oxygen supply has ceased, the muscle goal is to keep the homeostasis and maintain ATP levels. The initial system of ATP production is via the phosphagen system [46], in which a phosphate is transferred from phosphocreatine (PCr) to ADP by the action of creatine kinase; as a result creatine and ATP are generated, but supplies deplete quickly [47]. As the ATP is consumed, the $\mathrm{PCr}$ is depleted, while ADP and phosphate are accumulated. As additional source of ATP, it can be generated by the myokinase reaction (2ADP $\leftrightarrow \mathrm{AMP}+\mathrm{ATP})$. After that, the AMP is rapidly deaminated to generate inosine monophosphate (IMP) by means of AMP deaminase.

Glycogen is then metabolised via anaerobic pathways with the aim of generating the needed ATP but is considerably less efficient compared to aerobic conditions: $38 \mathrm{~mol}$ of ATP against only $3 \mathrm{~mol}$ of ATP from mol of glucose-1-P from glycogen. Nonetheless, as mentioned before, the conversion rate is better under anaerobic conditions. Glycogen phosphorylase seems to be the ratelimiting enzyme in glycolysis; glycogen concentration, glycogen structure, and glycolytic rate might have a positive association [48]. Energy sources within the muscle (creatine phosphate, glycogen, glucose, ATP, ADP, and adenosine monophosphate (AMP)) are depleted, and lactic acid (from glycogen) and hypoxanthine (from ATP) are produced and accumulated [48]. The combined action of all these enzymes increases the glycogen degradation, yielding lactate and $\mathrm{H}^{+}$. Finally, the ATP hydrolysis, which yields ADP, phosphate, and $\mathrm{H}^{+}$, accelerates the $\mathrm{pH}$ drop in muscle. All these factors in combination exert an effect on the $\mathrm{pH}$ decline, thus affecting the meat quality development [49]. As lactate accumulates, a concomitant drop in muscle $\mathrm{pH}$ takes place. Any reaction that modulates the postmortem metabolism by enhancing the ATP production and altering the $\mathrm{pH}$ decline will impact on the meat quality development [50].
Once the $\mathrm{pH}$ drops to the isoelectric point (pI) of the main proteins, especially myosin $(\mathrm{pI}=5.3)$, a loss in the ability of these proteins to retain the water takes place [51]. The repulsion between the proteins decreases resulting in a tighter packing of the muscle fibres, reducing the space that separates myofibrils. Consequently, fluids between myofilaments are forced into the extramyofibrillar space, which is held in place by capillary forces [52]. The ability of meat to retain this fluid when a force is applied is termed as the water holding capacity (WHC) of meat [53], being an important attribute from a meat quality standpoint as it is related with textural and sensory characteristics such as tenderness and juiciness, among others. Factors that alter the gap between the fibres can affect the amount of water that is immobilised. The main extrinsic and intrinsic factors affecting the spatial order of the proteins include (1) $\mathrm{pH}$ changes; (2) the presence of divalent cations ( $\mathrm{Mg}$ and $\mathrm{Ca}$ ); (3) denaturing conditions (rapid $\mathrm{pH}$ declines while temperature is still high); and (4) the presence of plasticising agents such as ATP, enzymes as ATPase, and necessary cofactors that prevents myofibrillar protein crosslinking $[28,54]$. Immediately after slaughter, meat has excellent WHC due to the combination of high $\mathrm{pH}$ and high levels of ATP. However, over the subsequent $12-24 \mathrm{~h}$, WHC decreases because of the enzymatic breaking down of ATP and the muscle acidification due to lactic acid accumulation. Rapid postmortem glycolysis is led by alterations in carcass temperature (which can reach values of $42^{\circ} \mathrm{C}$ in the first $45-65$ minutes after slaughter) and is related with high drip loss, poor WHC, and pale colour. These conditions together generate what is known as pale, soft, and exudative (PSE) meat. Even if the final $\mathrm{pH}$ is within the normal range, WHC is too low in these cases. It has been reported [55] that high stress conditions before slaughter decreased muscle glycolytic potential, leading to increases in plasma lactate, muscle temperature, cortisol, rate of $\mathrm{pH}$ decline, ultimate $\mathrm{pH}$, and yellowness of meat [55].

With ATP becoming depleted, the ionic equilibrium in the muscle cell is disrupted due to $\mathrm{Na} / \mathrm{K}$ being unbalanced and Ca pumps interrupting the cellular activity. A relaxed animal contains approximately $4-10 \mathrm{mmol}$ ATP per $\mathrm{kg}$ of muscle [48]. After slaughter, the subsequent anaerobic glycogenolysis keeps the ATP concentration constant for a short time. When glycogen reaches around $50 \%$ of its original value, the ATP level starts to fall along with the $\mathrm{pH}$ [48]. When the temperature drops below $15^{\circ} \mathrm{C}$ and the ATP concentration is under a certain level, the calcium pump is unable to remove the calcium from the sarcoplasmatic reticulum, resulting in a build-up of calcium. This prevents proteins related with muscle movement-actin and troponin-from interacting, since the myosin will not be able to release from actin, impeding muscle relaxation, and therefore, the fibres will remain contracted. When the $\mathrm{pH}$ of meat drops to 5.9 and ATP is lower than $1 \mu \mathrm{mol} / \mathrm{g}$, rigor mortis commences.

It is then clear how the conversion of muscle to meat is a key process that affects several meat eating quality attributes. A successful determination of the compounds involved in this conversion can lead to a better understanding of not 
only the factors affecting the process per se but also the relationship with endpoint eating quality attributes such as juiciness, tenderness, and chewiness. In the next section, we review how these metabolites can be determined.

\section{Biochemical Methods: Quantification of Molecules and Metabolites from the Glycolytic Pathway}

In order to early predict meat quality characteristics such as texture, numerous methods have been developed with the aim of determining the concentration and activity of the molecules and enzymes involved in the glycolysis process. A scheme showing the relationships between the different metabolic pathways; analytes and enzymes involved; $\mathrm{pH}$ values; ATP, inosine, glycogen, glucose, and lactate levels; and meat defects is presented in Figure 1. The analysis of metabolites as a predictive tool to estimate the final tenderness is still not having high correlation values, as stated by Muchenje et al. [56] and Lahucky et al. [57]. For instance, these authors found poor correlation between objective texture measurements (Warner-Bratzler shear force (WBSF)) and glycogen amount premortem and at $1 \mathrm{~h}, 3 \mathrm{~h}$, and $48 \mathrm{~h}$ postmortem. However, the molecules and metabolites from the glycolytic pathway involved in the rigor and pre-rigor are clearly related with meat quality as they have good correlation with both PSE and DFD (dark, firm, and dry) meats; they can be useful as meat quality defect biomarkers. The presence of meat defects causes important financial loss to the meat industry [13-16]; in this regard, DFD defects have been reported in the main meatproduction species with exception of horse [58], while PSE meat has been reported in pig, cattle [59], turkey [60], chicken [61], and ostrich [62].

Numerous biochemical measurements have been developed with the aim of determining the concentration and activity of the molecules and enzymes involved in the glycolysis process, and these methods could be deemed indirect measures of meat quality, as they involve analysing biochemical markers of the ongoing muscle-to-meat conversion. Even though the analysis of these metabolites has not showed a significant correlation with objective tenderness, their involvement in the muscle-to-meat conversion cannot be neglected. While correlations of single metabolites have not been successful, better results are to be expected from a more holistic approach. Furthermore, in addition to their ability to predict meat quality defects, there is still room for research on their capacities to predict subjective eating quality measurements. Objective texture measurements do not explain full meat eating quality characteristics.

The most common methods to determine the glycolytic potential and the activity of the most important enzymes involved in the process of glycogen metabolism under anaerobic conditions are listed below. The methods are divided into three groups: (1) quantification of molecules and metabolites; (2) enzymatic activity assays (Tables 1 and 2, respectively); and finally (3) new online methods.

\subsection{Quantification of Molecules and Metabolites}

3.1.1. Glycogen, Reducing and Phosphorylated Sugars, and Lactate. Table 1 gives a general overview of many of the methods currently used for analysing the products of postmortem glycolysis. As a general rule, samples must be immediately frozen using liquid nitrogen and then stored at temperatures around $-80^{\circ} \mathrm{C}$. This is to halt enzymatic reactions and to try to preserve the actual amount of glycogen, glucose, and other compounds of interest. Then, depending on the analyte, an extraction process must be carried out which typically involves a deproteinisation step using $\mathrm{HClO}_{4}$. This is the underlying approach carried out by Choe et al. [63] modified from Dreiling et al. [64], in their determination of glycogen, who describe their extracted supernatants $(0.4 \mathrm{~mL})$ being combined with iodine solutions $(2.6 \mathrm{~mL})$ before determining concentrations from a glycogen standard curve. Alternatively, Chan and Exton [65] describe the measurement of initial glycogen through stoichiometry by determining both glycogen and glucose contents. In this two-stage approach, glycogen was extracted after washing in cold ethanol in stage one, while an enzyme digestion was employed to extract the glucose before being determined by Glucose PAP kit (spectrophotometric assay based on glucose oxidase and Trinder reaction where the end product is quinoneimine dye [66]). The determination of the two forms of glycogen (PG and MG) was described by Ferguson et al. [43]. After the extraction, the supernatant $(100 \mu \mathrm{l})$ was used for the determination of MG and the pellet was used for PG. Further incubation, neutralization, and centrifugation steps occurred before the total glucose concentration of the two fractions was determined. Choe et al. [63] and Apaoblaza et al. [67] described the determination of lactate using commercial kits (Boeringer-Mannheim, Germany, and liquiform lactate, Labtest Ref. 116, respectively), while Henckel et al. [68] terminated the extraction prior to centrifugation by adding $1 \mathrm{ml}$ of $2 \mathrm{M} \mathrm{KHCO}_{3}$, before measuring the lactate content by the method of Passonneau and Lowry [69]. For the determination of reducing and phosphorylated sugars, Aliani et al. [70] described the combination of two experiments to facilitate a common extraction procedure for sugars and nucleotides. This enabled one extract to be used for all these analytes, economising on chemicals and time. Aliquots of extracted chicken muscle filtrate (Table 1) were resin-treated to remove any interfering compounds and analysed (as described by Aliani and Farmer [76] using a modified resin, i.e., Marathon WBA ion-exchange resin). A secondary aliquot $(1.5 \mathrm{ml})$ was used to analyse phosphorylated sugars by enzymatic treatment using sodium carbonate buffer ( $50 \mathrm{mM}$ containing $\mathrm{MgCl} 20.5 \mathrm{mM}$ at $\mathrm{pH} 9.2$ ) to improve peak separation.

3.1.2. Nucleotides, Glycolytic Rate, and Minerals. The nucleotide ATP is the main source of energy for the muscle and the driver of the $\mathrm{Na} / \mathrm{K}$ and calcium pumps, powering contraction and relaxation of the muscle. In the very early postmortem stage, ATP concentration is apparently stable due to its formation from the creatine phosphate through 


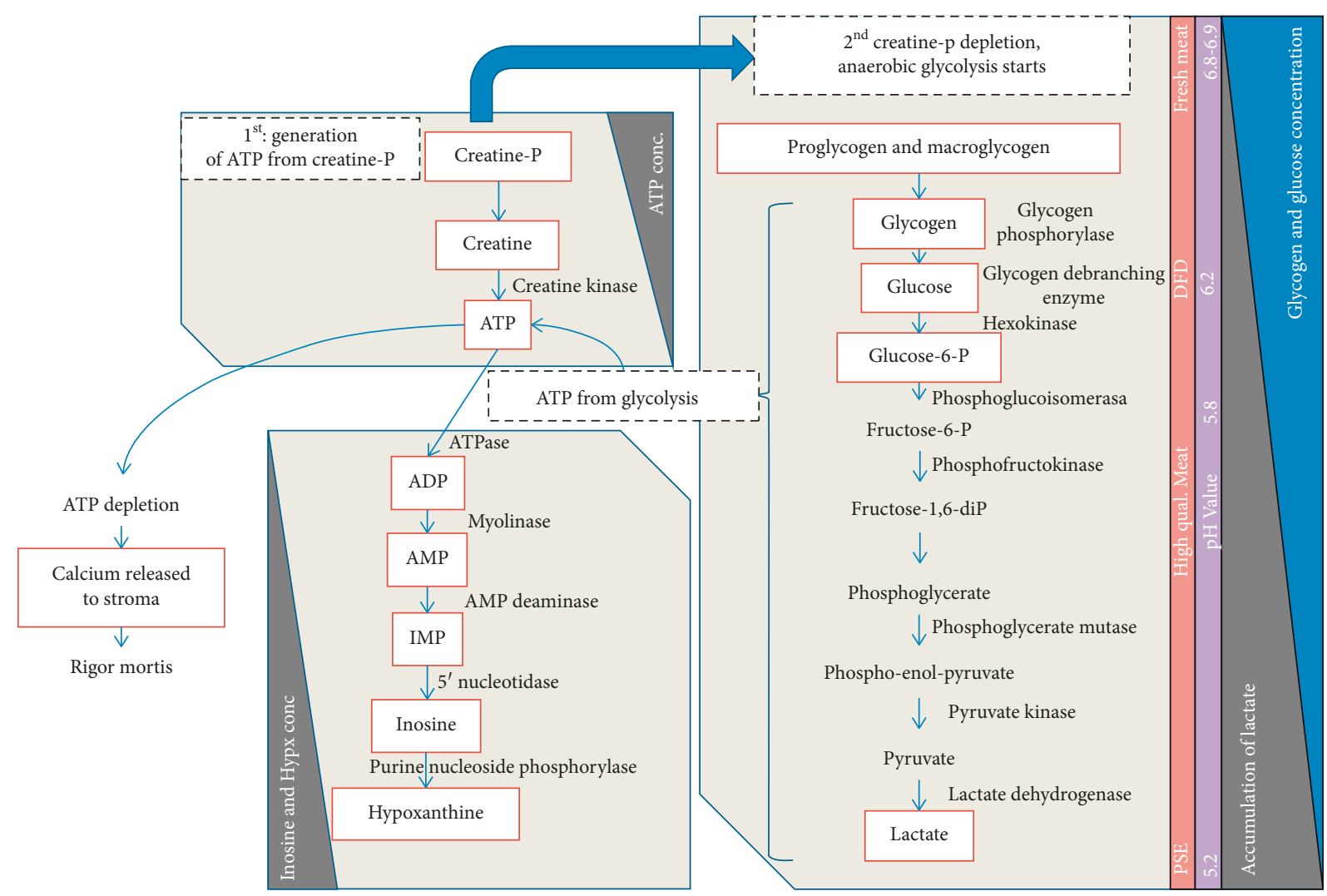

FIGURE 1: Compounds, enzymes, and metabolic pathways involved in the rigor mortis process. Enzyme activity currently assayed is given in blue letters and compounds currently quantified are in red border.

creatine kinase and anaerobic glycolysis routes. Once these sources are exhausted, ATP concentration starts to drop by converting to other compounds such as ADP, AMP, IMP, inosine, and hypoxanthine. Whereas ADP, AMP, and IDP are intermediates and their concentrations are negligible after $24-48 \mathrm{~h}$ and inosine and hypoxanthine experience a substantial increase as muscle is aged. Depletion of ATP in PSE muscle is very rapid, and as commented before, the rate is even faster at high temperatures. England et al. [75] reported that a decreased activity in AMP deaminase could extend the postmortem glycolytic process, which results in a lower $\mathrm{pH}$. Initially, the measurement of $\mathrm{pH}$ at $45 \mathrm{~min}$ postmortem was considered as a valid detector for PSE meat but, it is now clear, that using this measurement alone leads to gross classification errors. As a result, several methods based on the analysis of nucleotides and nucleosides have been developed in order to predict meat quality. Traditionally, ion-exchange chromatography was used to analyse ribonucleotides and related compounds (e.g., ATP, ADP, AMP, IMP, inosine, hypoxanthine, and creatine), but this was time-consuming and the resolution was poor. Currently, HPLC coupled to reverse-phase columns have given good analytical separations and recoveries [68,71].Common to these studies was the use of low molarity phosphate buffers and methanol as solvents and similar column lengths (150-250 mm). Henckel et al. [77] described the use of an isocratic method using a flow gradient $(0.5-1.5 \mathrm{~mL} / \mathrm{min})$, while Battle et al. [71] and Aliani et al. [70] used solvent gradients for their separations. It has been shown that the ATP level in PSE meat at $4 \mathrm{~h}$ postmortem is almost ten times lower than that of normal meat; as a consequence, IMP, inosine, and hypoxanthine are found in higher quantities in PSE meat. Rapid methods based on the measurement of the $R$ value have been developed (Table 1). These methods analyse the ratio between inosine-related and adenosinerelated compounds, which can be easily measured in meat extracts at 250 and $260 \mathrm{~nm}$ [63]. Furthermore, they have shown good correlations with meat quality when meat is analysed within the first 8 hours postmortem. In the absence of ATP, the cessation of the calcium pumps results in a build-up of calcium in the sarcoplasmic reticulum, making muscle relaxation impossible, i.e., onset of rigor mortis. Young \& Lyon [32] discussed the extraction and determination of calcium ions using atomic absorption spectroscopy.

3.2. Enzymatic Activity Assay. As it has been stated, besides analysing the content of metabolites which have a role in the postmortem process, determining the activity of the enzymes involved in the transformation of such molecules is essential to understand what the real state of the muscle is, during its transformation into meat. Not all the enzymes involved in the process can be currently analysed; however, available methods for some of them have been reported, for example, glycogen debranching enzyme [67, 74], glycogen 
TABLE 1: Direct chemical measurements of molecules and metabolites involved in post-mortem glycolysis.

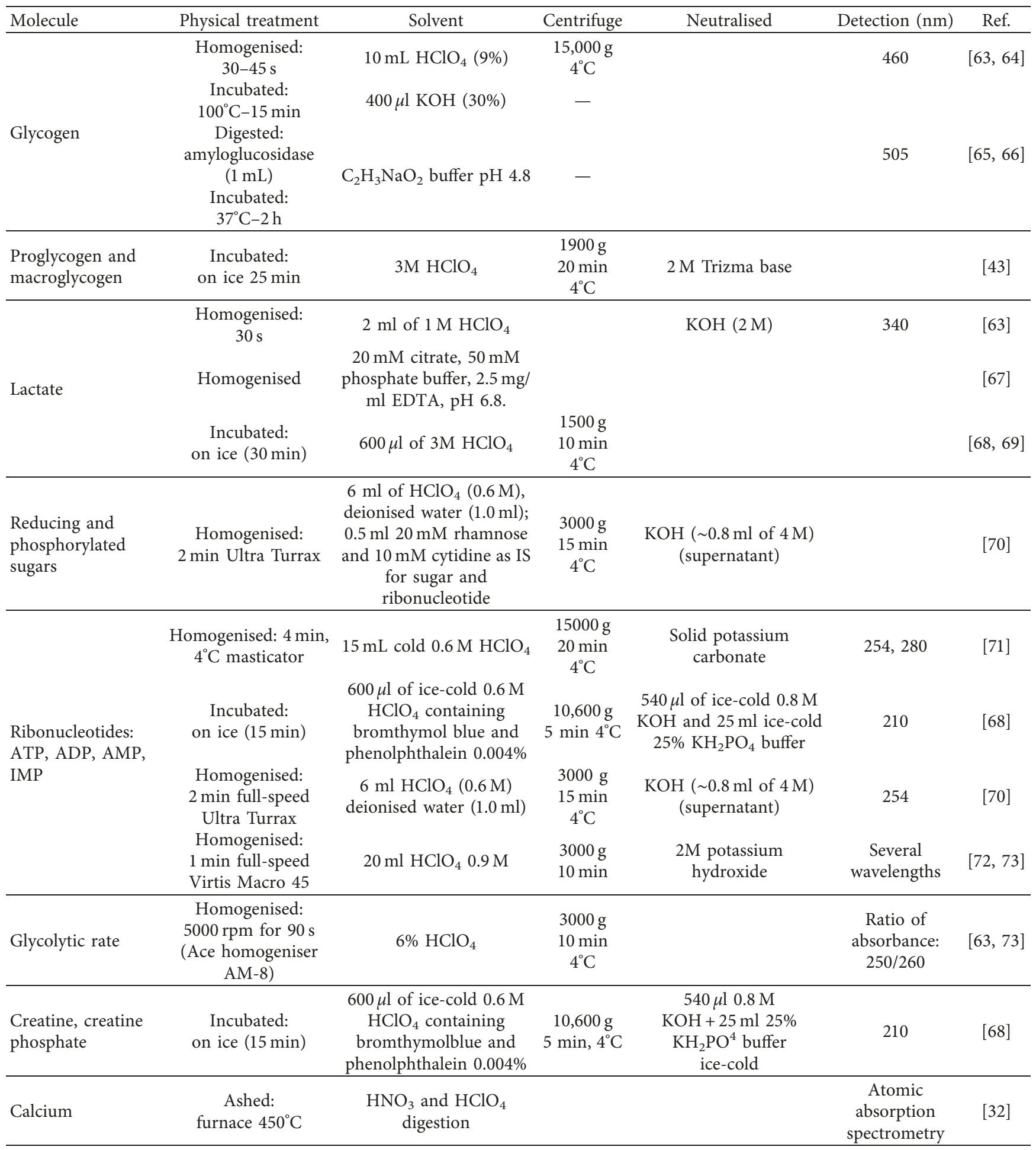

phosphorylase [67, 75], AMP kinase (AMPK) [67], phosphofructokinase, pyruvate kinase, AMP deaminase [75], or phosphoglucoisomerase [78]. These methods are summarised in Table 2. Most of these methods are based on the extraction of the active enzyme in an appropriate buffer providing the optimum medium (co-factors and $\mathrm{pH}$ stability) to observe the activity of extracted enzymes. A measurement of the "in vitro" activity of these enzymes is then performed using specific subtracts from each of the particular enzymes under study. Subsequently, either the substrate depletion or product formation can be monitored by means of colorimetric methods or by HPLC analysis.

3.3. Online Techniques of Metabolic Pathways Analytes Involved in Pre-Rigor and Rigor Stages. The main problem with 
TABLE 2: Methods employed for enzymatic activity assays.

\begin{tabular}{|c|c|c|c|c|c|}
\hline Enzyme & $\begin{array}{l}\text { Homogenization/other physical } \\
\text { treatements }\end{array}$ & Buffer & Assay & Detection (nm) & Ref. \\
\hline \multirow[t]{2}{*}{$\begin{array}{l}\text { Glycogen } \\
\text { debranching enzyme }\end{array}$} & $20 \mathrm{~min}, 18,000 \mathrm{rpm}$ & $\begin{array}{c}137 \mathrm{mM} \mathrm{NaCl}, 1 \mathrm{mM} \mathrm{MgCl}_{2}, 1 \% \\
\mathrm{NP}^{40}, 10 \% \text { glycerol, } 2 \mathrm{mM} \text { PMSF} \\
10 \mathrm{mM} \mathrm{Na} \mathrm{P}_{2} \mathrm{O}_{7}, 2.5 \mathrm{mM} \text { EDTA, } \\
10 \mu \mathrm{g} / \mathrm{ml} \mathrm{Aprotinin}, 10 \mu \mathrm{g} / \mathrm{ml} \\
\text { Leupotinin, } 100 \mathrm{nM} \cdot \mathrm{NaF}\end{array}$ & $\begin{array}{l}\text { Glucose } \\
\text { release }\end{array}$ & PAP kit & {$[67]$} \\
\hline & Ultra tTurrax + centrifugation & $\begin{array}{c}0.05 \% \mathrm{KHCO}_{3}+0.004 \mathrm{M} \text { EDTA } \\
\left(\mathrm{pH} 7.8 \text { at } 25^{\circ} \mathrm{C}\right)\end{array}$ & $\begin{array}{l}\text { Glucose } \\
\text { release }\end{array}$ & $\begin{array}{l}\text { Iodine reagent, } \\
\text { Abs. } 525\end{array}$ & {$[74]$} \\
\hline $\begin{array}{l}\text { Glycogen } \\
\text { phosphorylase }\end{array}$ & $100 \mathrm{mM} \mathrm{K}_{2} \mathrm{HPO}_{4}$ ice-cold, pH 7.4 & $\begin{array}{c}50 \mathrm{mM} \text { Tris (pH 7.6), } 5 \mathrm{mM} \\
\text { imidazole, } 2 \mathrm{mM} \text { EDTA, } 10 \mathrm{mM} \\
\mathrm{KH}_{2} \mathrm{PO}_{4} / \mathrm{Na}_{2} \mathrm{HPO}_{4}(\mathrm{pH} 7.6) \\
1.4 \mathrm{mM} \text { mercaptoethanol, } 0.6 \mathrm{mM} \\
\text { NADP, } 0.05 \mathrm{mM} \text { glucose-1,6- } \\
\text { diphosphate, } 2 \mathrm{mM} \text { AMP, } 0.65 \mathrm{U} \\
\text { phosphoglucomutase, } 0.28 \mathrm{U} \mathrm{G}-6- \\
\mathrm{P} \text { dehydrogenase } \\
50 \mathrm{mM} \mathrm{K} \mathrm{HPO}_{2}, 2 \mathrm{mg} / \mathrm{mL} \\
\text { glycogen, } 1.3 \mathrm{mM} \mathrm{MgCl}, 0.1 \mathrm{mM} \\
\text { EDTA, } 0.5 \mathrm{mM} \mathrm{NADP}, 200 \mathrm{mM} \\
\text { MES (pH 6.8), } 1 \mathrm{U} / \mathrm{mL} \\
\text { phosphoglucomutase and } 1 \mathrm{U} / \mathrm{mL} \\
\text { G-6-P dehydrogenase }\end{array}$ & Abs. increase & Abs. 340 & {$[75]$} \\
\hline \multicolumn{6}{|l|}{ AMP- kinase } \\
\hline Phosphofructokinase & $100 \mathrm{mM} \mathrm{K}_{2} \mathrm{HPO}_{4}$ ice-cold, pH 7.4 & $\begin{array}{l}120 \mathrm{mM} \text { MES (pH 6.5), } 3.2 \mathrm{mM} \\
\mathrm{MgSO} 4,2 \mathrm{mM} \text { ATP, } 0.15 \mathrm{mM} \\
\text { AMP, } 1 \mathrm{mM} \text { NADH, } 3 \mathrm{mM} \\
\text { fructose 6-phosphate, } 2 \mathrm{U} / \mathrm{mL} \\
\text { triosephosphate isomerase, } 1 \mathrm{U} / \\
\mathrm{mL} \text { glycerol-3-P dehydrogenase } \\
\text { and } 1 \mathrm{U} / \mathrm{mL} \text { aldolase }\end{array}$ & & Abs. 340 & {$[75]$} \\
\hline Pyruvate kinase & $100 \mathrm{mM} \mathrm{K}_{2} \mathrm{HPO}_{4}$ ice-cold, pH 7.4 & $\begin{array}{c}120 \mathrm{mM} \text { MES (pH 6.5), } 100 \mathrm{mM} \\
\mathrm{KCl}, 10 \mathrm{mM} \mathrm{MgCl}, 1.25 \mathrm{mM} \\
\mathrm{ADP}, 1 \mathrm{mM} \text { NADH, 0.5 mM PEP } \\
\text { and } 2 \mathrm{U} / \mathrm{mL} \text { lactate dehydrogenase }\end{array}$ & $\begin{array}{l}\text { PEP conc. } \\
\text { decrease. }\end{array}$ & Abs 340 & {$[75]$} \\
\hline AMP deaminase & $\begin{array}{c}\text { Ffrozen powdered muscle }+ \\
90 \mathrm{mM} \mathrm{K}_{2} \mathrm{HPO}_{4} \mathrm{pH} 6.5,180 \mathrm{mM} \mathrm{KCl}, \\
\text { and } 0.1 \mathrm{mM} \text { dithiothreitol }\end{array}$ & $\begin{array}{l}200 \mathrm{mM} 2 \text {-( } \mathrm{N} \text {-morpholino }) \\
\text { ethanesulfonic acid } 150 \mathrm{mMKCl} \text {, } \\
\text { and } 10 \mathrm{mMAMP} \text { at } \mathrm{pH} 6.5\end{array}$ & AMP level & HPLC & {$[75]$} \\
\hline $\begin{array}{l}\text { Phosphogluco } \\
\text { isomerase }\end{array}$ & $100 \mathrm{mM} \mathrm{K}_{2} \mathrm{HPO}_{4} \mathrm{pH} 7.4$ & $\begin{array}{c}200 \mathrm{mM} \mathrm{MES}, 10 \mathrm{mM} \mathrm{Na}_{2} \mathrm{HPO}_{4} \\
5 \mathrm{mM} \mathrm{MgCl} 2,60 \mathrm{mM} \mathrm{KCl}, 0.5 \mathrm{mM} \\
\mathrm{NAD}^{+}, 25 \mathrm{mM} \text { glycogen, } 25 \mathrm{mM} \\
\text { carnosine, } 30 \mathrm{mM} \text { creatine, } 10 \mathrm{mM} \\
\text { gG-6-P and } 10 \mathrm{mM} \mathrm{C}_{2} \mathrm{H}_{3} \mathrm{NaO}_{2} \text { at } \\
\text { pH } 5.5-6.0\end{array}$ & F-6-P level & & {$[75]$} \\
\hline
\end{tabular}

the traditional biochemical methods discussed above are that they are time-consuming, and biomarkers should be easy and fast to determine and preferably online. In this regard, later studies based on spectroscopy indicate the possibility to determine early postmortem metabolic analytes using Raman spectroscopy. The research of Scheier et al. [79] on porcine semimembranosus muscle indicates a good agreement between measured biochemical parameters and simulated Raman. In this regard, in the pre-rigor and rigor frame, they were able to find clear signals of phosphocreatine, ATP, IMP, and $\alpha$-helical proteins (correlated with glycogen to lactate). Sheier et al. [79] provided a first semiquantitative description of the early postmortem Raman spectra of meat which show potential for fast detection of the metabolic state of meat and hence for the identification of meat quality defects.

\section{Mechanical Methods}

As the muscle enters rigor mortis, it loses its ability to relax (until further enzyme activity degrades the complex), which is of critical importance for meat quality since it increases the toughness of the meat. It is clear that the tenderness and other palatability characteristics depend directly on the rigor mortis state. For this reason, an early mechanical measurement of this phenomenon will help to predict the final meat characteristics, in this case mainly texture-related characteristics. Contrary to biochemical methods, mechanical methods provide a direct 
measurement of the meat toughness "at rigor" that is directly related with the final texture and palatability of the steak $[80,81]$. Physical methods have been used or have the potential to be used to determine the texture during onset and progress of rigor mortis include elasticity, ultramicroscopic observation, tensile and adhesive properties, myotonometry, isometric tension, NMR, NIR, and sonoelasticity.

These studies have given us a profound understanding of rigor mortis in skeletal muscles, especially "red" muscles, and a technological guidance to control meat quality [82]. However, these studies are usually done on single muscle fibres or single muscle bundles, and thus, it is difficult to give an accurate depiction of rigor mortis for an intact muscle. The advantage of many of the techniques discussed here is that they are not destructive. Damez and Clerjon [83] published a review gathering available biophysical methods related to meat structure. In the present article, we expand the array of mechanical methodologies used for meat quality prediction during rigor mortis.

4.1. Elasticity. Measuring the elastic properties of the muscle was firstly investigated in the 1930s, culminating with the development of a "rigor-meter" instrument. The method is based on the accurate measurement of muscle length extension when a fixed amount of force is applied to the muscle and the extent to which the original length is recovered after the force is removed. Meat rich in ATP is able to endure significant stretching, while maintaining its ability to recover its original shape. However, when ATP becomes depleted, the muscle is only very slightly extensible. Muscle strips are maintained in an anaerobic atmosphere to prevent aerobic surface resynthesis of ATP [84]. Despite this method being created to concretely to evaluate the rigor phase, there have been not studies relating rigor elasticity with the final meat texture.

4.2. Isometric Tension. The principle of isometric tension is the application of a load to a muscle that is too great to be moved, and in response, the muscle generates increasing tension as it attempts to shorten. The isometric tension (IT) is expressed as force per unit area and the muscle shortening $(\mathrm{SH})$ as percentage decrease in the length of the muscle. The isometric tension test was developed by Rheologica Instruments (Lund, Sweden) in conjunction with the Swedish Meat Research Institute. It is a unique analytical instrument (RigoTech Muscle Texture Analyser) with the aim of determining the optimum cooling conditions for meat tenderness. Tornberg et al. [85] describe the collection of data with strips $(35 \mathrm{~mm} ; 1.5 \pm 2 \mathrm{~g})$ of muscle tissue (M. longissimus dorsi). The isometric and isotonic recording components record the readings every $5 \mathrm{~min}$ in a closed chamber at a controlled temperature. Regarding the potential of isometric tension measurements as predictive method for final meat quality, a good correlation has been established between isometric measurements and other parameters such as myofibrillar and sarcomere length, a good predictor of meat tenderness [86]. On the other hand, trials comparing muscles with different shortening levels due to differences in temperature found a good correlation between isometric measurement and toughness even after 14 days of storage on some muscles [87]. On the contrary, Devine et al. [88] found that meat going into rigor at around $15^{\circ} \mathrm{C}$ is equally tender at 14 of ageing, independently of isometric measurements (restrained and unrestrained muscles) implying higher enzymatic importance at these temperatures.

4.3. Myotonometry. Vain et al. [89] describe the use of a myotonometer, a handheld instrument used to grade rigor mortis. The instrument delivers a mechanical impact against the muscle to which there is a damped vibratory response. This information is received and treated mathematically, i.e., the period and logarithmic decrease/decay of the vibrations are found to change with the development of rigor mortis, yielding quantitative information on muscular stiffness. It is particularly useful in determining the time of death. To-date, there is no study relating this technique with final meat quality.

4.4. Ultrasound Technologies. Ultrasonic properties have been used to assess physicochemical properties of many foods including meat. For the quality evaluation of muscle foods, mainly two methods have been employed: ultrasonic spectral analysis [90] and ultrasonic elastography [91]. The former is based on the differences in some ultrasonic parameters, such as velocity, attenuation, and backscatter intensity, due to differences in muscle composition and structure which generate the differences in wave propagation. Ultrasound has been applied to determine meat quality of different individual muscles [92-94], but it has also been used for predicting meat quality in live animals $[95,96]$ and carcasses $[97,98]$. The ultrasound probe placed in the inside of the carcass has proved to reveal promising results about intramuscular fat determination in pork carcasses [98].

Ultrasound elastography originates from the medical diagnostic field; however, it is beginning to emerge as a diagnostic tool for evaluation of the skeletal muscle mechanical properties. Shear wave elastography (SWE) is an ultrasoundbased technique that uses the propagation of remotely induced shear waves to characterise the mechanical properties of the tissue. Using the shear wave propagation and the tissue density, the shear modulus is calculated and can be correlated with tensile load. The main drawback of this promising technology is the cost, which at this point is too high for industry application. Eby et al. [99] described an experimental setup combining traditional materials testing techniques with SWE. The tensile test was applied to porcine brachialis whole muscle tissue at $1.15 \%$ of the initial length per second with simultaneous ultrasound measurements. The orientation of the ultrasound transducer to the muscle fibre direction played a key role in the importance of the obtained data; at $45^{\circ}$ and perpendicular to the fibres, the shear waves did not propagate properly, whereas when parallel there was a positive correlation between SWE and the tensile load.

4.5. Sonoelasticity. Sonoelasticity is a nondestructive method that combines ultrasonic waves with Doppler imaging to indicate differences in biological tissues. Ayadi et al. 
[100] used this technique on biceps femoris muscle of beef to monitor changes during rigor and ageing. The authors applied perturbation $(80$ and $100 \mathrm{~Hz}$ ) and ultrasound waves $(5 \mathrm{MHz})$ and recorded different sonoelastic parameters, including velocity and attenuation. In addition, the authors also took linear compression measurements and hourly $\mathrm{pH}$ determinations. When these were compared with sonoelasticity parameters, significant and higher correlations were obtained (coefficient of correlation up to 0.97). In the same study, the authors were also able to detect the mechanical textural changes during ageing with the sonoelasticity parameters. To our knowledge, there are no studies relating the results obtained by sonoelasticity in pre-rigor and rigor with final muscle tenderness or other meat quality characteristics.

4.6. Laser Air-PuffSystems. This technique has been adopted from the fruit processing industry, where it is applied for measuring the firmness of peaches or kiwis [101]. The potential application of a laser pressurised air system to assess poultry meat tenderness was investigated by Lee et al. [102]. Lee et al. [102] carried out experiments where raw chicken breasts (deboned at $1.25,4$, or $24 \mathrm{~h}$ postmortem) were longitudinally scanned on a conveyor belt by a laser distance sensor in order to obtain overall shape profiles; subsequently, they were scanned again with a pressurised source of air $(206.8 \mathrm{kPa})$. The two resulting profiles were superimposed to quantify the amount of deformation caused by the application of pressurised air. Five parameters including the height and length of each fillet were calculated and used to establish a model to predict tenderness. Even though this technique has only been applied to chicken fillets, there is potential for developing it for implementation in the abattoir line.

4.7. Texturometer Analysis. The use of texture analysers is well documented for meat texture determination in lab [103-105]. However, Li et al. [106] used a texture analyser (TAXT2i, Stable Micro Systems Ltd., Godalming, UK) to monitor changes during rigor mortis or thaw rigor in chicken breast muscle. Plastic film-wrapped samples were penetrated by a cylindrical probe to a distance of $2 \mathrm{~mm}$ at a velocity of $1 \mathrm{~mm} / \mathrm{s}$ and a trigger force of $0.02 \mathrm{~N}$. The probe was held for $48 \mathrm{~h}$, and data were acquired at 0.1 points per second. Representations of the force as function of time provided information of the differences in rigor mortis and thaw rigor at two different temperatures $\left(4^{\circ} \mathrm{C}\right.$ and $\left.15^{\circ} \mathrm{C}\right)$. It was found that, even at lower temperatures where the process of rigor mortis takes longer times, the final contracture reached the same extent than at the higher temperature. When the rigor commences, the sarcomere shortens and the muscle fibre diameter increases and hence the force is higher. When the rigor finishes, the sarcomere length increases and the diameter decreases producing a decrease in the force. Texturometer analyses at pre-rigor and rigor phases have been used exclusively to monitor the process of rigor, and no experiments have been found relating these early measurements with final meat quality parameters.

\section{Rapid Nondestructive Techniques Performed Online}

The use of rapid nondestructive technologies can be applied to early predict meat quality parameters. They offer the ability to increase the control checks during meat processing and retailing but can also present an opportunity to evaluate meat quality right after slaughter. Apart from the use of Raman spectroscopy (section 3.3.) to determine biochemical parameters, there are a few other technologies based on imaging and spectroscopy that have being recently implemented or are under investigation for the evaluation/ prediction of final texture.

5.1. X-Ray Analysis. Two main technologies based on X-ray have been used for meat quality analysis: computed tomography (CT) and dual X-ray absorptiometry (DXA). CT is widely used in the medical field, but it has also been used as a measuring tool of animal body composition (lean, fat, and bone) since the early 80 s [107]. It has also been employed for meat quality determination in pigs and lambs by means of intramuscular fat $[108,109]$. The main drawbacks of this technique are the generated radiation and the small aperture of the actual devices that make it impossible to scan full bovine carcasses.

DXA couples the information acquired at two energy levels (high and low) and was initially designed for the measurement of bone mineral density but later on was used for body composition. Kröger et al. [110] used DXA to predict tenderness in steaks obtaining a correlation of 0.69. A few years later, a patent was filed regarding the use of $\mathrm{X}$-rays to evaluate meat tenderness in meat products [111]. According to the author of the invention, the meat sample is analysed through an X-ray beam and the amount of radiation transmitted can be related to a characteristic of the shear force measured by Warner Bratzler. Even though this technique has been only applied to meat products, it could be potentially used on carcasses to have an earlier prediction of meat tenderness.

5.2. Video Image Analysis (VIA). VIA systems are based on the differences in light intensity received by a video camera and were developed specifically for beef carcass evaluation. Nonetheless, some specific systems have been also utilised to predict tenderness and marbling in beef [112] and pigs carcasses [113]. Usually in these systems, the camera is located at some distance from the rib eye section.

5.3. NIR and Vis-NIR Spectroscopy. Spectrophotometric methods use probes in contact with or penetrating into the meat [114]. Earlier pre-rigor analysis was applied between 2 and 4 hours postmortem by Rodotten et al. [115] using near-infrared spectroscopy (NIR), and their results showed a poor correlation coefficient with the final texture after 7 days ageing (0.47-0.55). Hoving-Bolink et al. [116] investigated the ability of visible-NIR spectroscopy (1 h postmortem in pork) to predict meat 
quality. Their results indicate a poor correlation between NIR and meat quality measurements. Vis-NIR spectroscopy has been also used to predict ultimate $\mathrm{pH}$ in beef [117], obtaining a prediction model able to correctly segregate $90 \%$ of the carcasses with high $(>5.8)$ or normal $\mathrm{pH}(<5.8)$.

5.4. Hyperspectral Imaging (HIS). HIS is a relatively modern technique that combines imaging and spectroscopic data. Applied on the ribeye surface of a hanging carcass, it was able to predict 14-day aged cooked beef tenderness with an accuracy of $86.7 \%$ [118]. $\mathrm{pH}$ and drip loss have been also assessed in different muscles and species $[119,120]$. As this technique stores enormous amount of data, the processing is paramount. With new data processing techniques and hardware and software improvements, this technique could be a potential technique for meat quality determination at an early stage; however, few experiments have been done during the onset and rigor stages. A thorough review of the application of HIS in red meat has been published by Xiong et al. [121].

\section{Conclusion}

It is long established that proteolysis is responsible for a considerable portion of postmortem tenderisation. However, of great importance are the stages that precede, namely, pre-rigor and rigor mortis stages. Increasing accuracy and sensitivity of chromatography systems have led to more accurate measurements of the biochemical compounds that underpin the transformation of muscle into meat, leading to a better understanding of their connection with the final meat eating quality attributes, namely, tenderness. Furthermore, the use of increasingly nondestructive mechanical or spectroscopic methods to monitor the physical changes brought on by rigor mortis could be used to evaluate and predict a different array of meat quality attributes. However, despite the high number of techniques reviewed in the present manuscript, there is no particular method (chemical or physical) that can accurately predict the final meat eating quality characteristics in the early postmortem period. Therefore, further research is needed where combinations of the methods here described, the incorporation of emerging tools as proteomics and metabolomics, or their correlation with sensory properties will be of benefit to accurately predict meat eating quality attributes.

\section{Conflicts of Interest}

The authors declare that they have no conflicts of interest.

\section{Acknowledgments}

L. Morán is contracted within the Consolidated Research Group Lactiker (Type A) funded by the Basque Government (IT944-16).

\section{References}

[1] C. H. Herrera-Mendez, S. Becila, A. Boudjellal, and A. Ouali, "Meat ageing: reconsideration of the current concept," Trends in Food Science \& Technology, vol. 17, no. 8, pp. 394-405, 2006.

[2] K. G. Ouali, "Future trends and consumer lifestyles with regard to meat consumption," Meat Science, vol. 74, no. 1, pp. 149-160, 2006.

[3] D. W. Pethick, A. J. Ball, R. G. Banks, and J. F. Hocquette, "Current and future issues facing red meat quality in a competitive market and how to manage continuous improvement," Animal Production Science, vol. 51, no. 1, pp. 13-18, 2011.

[4] A. Valfrè and F. Valfrè, "Effects of changing production methods on quality of meat, milk and eggs," Livestock Production Science, vol. 59, no. 2-3, pp. 165-182, 1999.

[5] C. Maltin, D. Balcerzak, R. Tilley, and M. Delday, "Determinants of meat quality: tenderness," Proceedings of the Nutrition Society, vol. 62, no. 2, pp. 337-347, 2003.

[6] S. N. Delday, M. Henchion, A. White, K. Brandon, and P. Allen, "Evaluation of beef eating quality by Irish consumers," Meat Science, vol. 132, pp. 118-124, 2017.

[7] L. Meinert, L. T. Andersen, W. L. P. Bredie, C. Bjergegaard, and M. D. Aaslyng, "Chemical and sensory characterisation of pan-fried pork flavour: interactions between raw meat quality, ageing and frying temperature," Meat Science, vol. 75, no. 2, pp. 229-242, 2007.

[8] C. Hartmann and M. Siegrist, "Consumer perception and behaviour regarding sustainable protein consumption: a systematic review," Trends in Food Science \& Technology, vol. 61, pp. 11-25, 2017.

[9] P. Sans and A. I. Sanjuán López, "Beef animal welfare, attitudes and Willingness to Pay: a regional comparison across the Pyrenees," Spanish Journal of Agricultural Research, vol. 13, pp. 11-21, 2015.

[10] A. Risius and U. Hamm, "The effect of information on beef husbandry systems on consumers' preferences and willingness to pay," Meat Science, vol. 124, pp. 9-14, 2017.

[11] C. Escriba-Perez, A. Baviera-Puig, J. Buitrago-Vera, and L. Montero-Vicente, "Consumer profile analysis for different types of meat in Spain," Meat Science, vol. 129, pp. 120-126, 2017.

[12] H. A. Montero-Vicente, A. N. Arnold, J. C. Brooks et al., "National beef tenderness survey-2015: palatability and shear force assessments of retail and foodservice beef," Meat and Muscle Biology, vol. 1, no. 1, pp. 138-148, 2017.

[13] H. J. Guise, "Problems of pigmeat production and processing: with particular reference to preslaughter handling," Royal Veterinary College (University of London), London, UK, 1990.

[14] R. G. Cassens, "Historical perspectives and current aspects of pork meat quality in the USA," Food Chemistry, vol. 69, no. 4, pp. 357-363, 2000.

[15] D. J. O'Neill, P. B. Lynch, D. J. Troy et al., "Influence of the time of year on the incidence of PSE and DFD in Irish pigmeat," Meat Science, vol. 64, pp. 105-111, 2003.

[16] J. F. Cassell, S. Dyson, P. D. Reiser et al., "Unlocking the secrets for pork quality," CSIRO Report on Research, vol. 21, pp. 79-85, 1991.

[17] P. E. Strydom, "Quality related principles of the South African beef classification system in relation to grading and 
classification systems of the world," South African Journal of Animal Science, vol. 41, pp. 177-193, 2011.

[18] R. J. Polkinghorne and J. M. Thompson, "Meat standards and grading," Meat Science, vol. 86, no. 1, pp. 227-235, 2010.

[19] P. D. Muir, J. M. Deaker, and M. D. Bown, "Effects of forageand grain-based feeding systems on beef quality: a review," New Zealand Journal of Agricultural Research, vol. 41, no. 4, pp. 623-635, 1998.

[20] J. Thompson, "Managing meat tenderness," Meat Science, vol. 62, no. 3, pp. 295-308, 2002.

[21] J.-F. Hocquette, R. Botreau, B. Picard, A. Jacquet, D. W. Pethick, and N. D. Scollan, "Opportunities for predicting and manipulating beef quality," Meat Science, vol. 92, no. 3, pp. 197-209, 2012.

[22] D. Dashdorj, T. Amna, and I. Hwang, "Influence of specific taste-active components on meat flavor as affected by intrinsic and extrinsic factors: an overview," European Food Research and Technology, vol. 241, no. 2, pp. 157-171, 2015.

[23] R. D. Warner, C. K. McDonnell, A. E. D Bekhit et al., "Systematic review of emerging and innovative technologies for meat tenderisation," Meat Science, vol. 132, pp. 72-89, 2017.

[24] J. F. Hocquette, R. Botreau, I. Legrand et al., "Win-win strategies for high beef quality, consumer satisfaction, and farm efficiency, low environmental impacts and improved animal welfare," Animal Production Science, vol. 54, no. 10, pp. 1537-1548, 2014.

[25] M. Koohmaraie, "Biochemical factors regulating the toughening and tenderization processes of meat," Meat Science, vol. 43, pp. 193-201, 1996.

[26] A. Ouali, C. H. Herrera-Mendez, G. Coulis et al., "Revisiting the conversion of muscle into meat and the underlying mechanisms," Meat Science, vol. 74, no. 1, pp. 44-58, 2006.

[27] M. L. Greaser, "Conversion of muscle to meat," Muscle as Food, pp. 37-102, 1986.

[28] E. H. Lonergan, W. Zhang, and S. M. Lonergan, "Biochemistry of postmortem muscle-lessons on mechanisms of meat tenderization,” Meat Science, vol. 86, pp. 184-195, 2010.

[29] M. Koohmaraie and G. H. Geesink, "Contribution of postmortem muscle biochemistry to the delivery of consistent meat quality with particular focus on the calpain system," Meat Science, vol. 74, no. 1, pp. 34-43, 2006.

[30] A. Lana and L. Zolla, "Proteolysis in meat tenderization from the point of view of each single protein: a proteomic perspective," Journal of Proteomics, vol. 147, pp. 85-97, 2016.

[31] C. M. Kemp and T. Parr, "Advances in apoptotic mediated proteolysis in meat tenderisation," Meat Science, vol. 92, no. 3, pp. 252-259, 2012.

[32] L. L. Young and C. E. Lyon, "Effect of calcium marination on biochemical and textural properties of peri-rigor chicken breast meat," Poultry Science, vol. 76, no. 1, pp. 197-201, 1997.

[33] D. Lomiwes, M. M. Farouk, G. Wu, and O. A. Young, "The development of meat tenderness is likely to be compartmentalised by ultimate $\mathrm{pH}$," Meat Science, vol. 96, no. 1, pp. 646-651, 2014.

[34] C. P. Young, G. H. Geesink, D. Collins, V. Hutton Oddy, and D. L. Hopkins, "Do sarcomere length, collagen content, $\mathrm{pH}$, intramuscular fat and desmin degradation explain variation in the tenderness of three ovine muscles?," Meat Science, vol. 113, pp. 51-58, 2016.

[35] T. Cramer, M. L. Penick, J. N. Waddell, C. A. Bidwell, and Y. H. B. Kim, "A new insight into meat toughness of callipyge lamb loins-the relevance of anti-apoptotic systems to decreased proteolysis," Meat Science, vol. 140, pp. 66-71, 2018.
[36] R. Jeantet, T. Croguennec, P. Schuck et al., Handbook of Food Science and Technology 3: Food Biochemistry and Technology, John Wiley \& Sons, Hoboken, NJ, USA, 2016.

[37] F. Toldrá, "Muscle foods: water, structure and functionality," Food Science and Technology International, vol. 9, no. 3, pp. 173-177, 2003.

[38] A. R. Pösö and E. Puolanne, "Carbohydrate metabolism in meat animals," Meat Science, vol. 70, no. 3, pp. 423-434, 2005.

[39] J. R. Zierath and J. A. Hawley, "Skeletal muscle fiber type: influence on contractile and metabolic properties," PLoS Biology, vol. 2, no. 10, article e348, 2004.

[40] K. Immonen, M. Ruusunen, and E. Puolanne, "Some effects of residual glycogen concentration on the physical and sensory quality of normal pH beef," Meat Science, vol. 55, no. 1, pp. 33-38, 2000.

[41] K. Immonen and E. Puolanne, "Variation of residual glycogen-glucose concentration at ultimate $\mathrm{pH}$ values below 5.75," Meat Science, vol. 55, no. 3, pp. 279-283, 2000.

[42] F. H. Larsen, B. Essén-Gustavsson, M. Jensen-Waern, R. Lametsch, A. H. Karlsson, and G. Lindahl, "Analysis of acid-soluble glycogen in pork extracts of TwoPRKAG3Genotypes by1H liquid-state NMR spectroscopy and biochemical methods," Journal of Agricultural and Food Chemistry, vol. 59, no. 22, pp. 11895-11902, 2011.

[43] D. M. Ferguson, B. L. Daly, G. E. Gardner, and R. K. Tume, "Effect of glycogen concentration and form on the response to electrical stimulation and rate of post-mortem glycolysis in ovine muscle," Meat Science, vol. 78, no. 3, pp. 202-210, 2008.

[44] D. R. Tume, "Skeletal muscle metabolism and plasticity," in Functional Metabolism, Regulation and Adaptation, WileyLiss Inc., Hoboken, NJ, USA, 2004.

[45] G. Monin and P. Sellier, "Pork of low technological quality with a normal rate of muscle $\mathrm{pH}$ fall in the immediate postmortem period: the case of the Hampshire breed," Meat Science, vol. 13, no. 1, pp. 49-63, 1985.

[46] S. K. Matarneh, E. M. England, T. L. Scheffler et al., "The conversion of muscle to meat," in Lawrie's Meat Science, pp. 159-185, Elsevier, Amsterdam, Netherlands, 2017.

[47] L. Guimarães-Ferreira, "Role of the phosphocreatine system on energetic homeostasis in skeletal and cardiac muscles," Einstein, vol. 12, no. 1, pp. 126-131, 2014.

[48] K. O. Honikel, "Conversion of muscle to meat glycolysis," in Encyclopedia of Meat Sciences, Academic Press, Oxford, UK, 2nd edition, 2014.

[49] T. L. Scheffler, S. C. Kasten, E. M. England, J. M. Scheffler, and D. E. Gerrard, "Contribution of the phosphagen system to postmortem muscle metabolism in AMP-activated protein kinase $\gamma 3$ R200Q pig Longissimus muscle," Meat Science, vol. 96, no. 2, pp. 876-883, 2014.

[50] T. L. Scheffler, A. L. Rosser, S. C. Kasten, J. M. Scheffler, and D. E. Gerrard, "Use of dietary supplementation with $\beta$-guanidinopropionic acid to alter the muscle phosphagen system, postmortem metabolism, and pork quality," Meat Science, vol. 95, no. 2, pp. 264-271, 2013.

[51] E. Tornberg, "Effects of heat on meat proteins-implications on structure and quality of meat products," Meat Science, vol. 70, no. 3, pp. 493-508, 2005.

[52] P. V. Tarrant, "Muscle proteins in meat technology," in Food Proteins, P. F. Fox and J. J. Condon, Eds., pp. 261-291, Applied Science Publishers, Essex, UK, 1982.

[53] K. L. Pearce, K. Rosenvold, and D. L. Hopkins, "Water distribution and mobility in meat during the conversion of muscle to meat and ageing and the impacts on fresh meat 
quality attributes-a review," Meat Science, vol. 89, no. 2, pp. 111-124, 2011.

[54] E. Andersen and S. M. Lonergan, "Mechanisms of waterholding capacity of meat: the role of postmortem biochemical and structural changes," Meat Science, vol. 71, no. 1, pp. 194-204, 2005.

[55] E. Hambrecht, J. J. Eissen, D. J. Newman, C. H. M. Smits, L. A. den Hartog, and M. W. A. Verstegen, "Negative effects of stress immediately before slaughter on pork quality are aggravated by suboptimal transport and lairage conditions," Journal of Animal Science, vol. 83, no. 2, pp. 440-448, 2005.

[56] V. Muchenje, K. Dzama, M. Chimonyo, P. E. Strydom, A. Hugo, and J. G. Raats, "Some biochemical aspects pertaining to beef eating quality and consumer health: a review," Food Chemistry, vol. 112, no. 2, pp. 279-289, 2009.

[57] R. Lahucky, O. Palanska, J. Mojto, K. Zaujec, and J. Huba, "Effect of preslaughter handling on muscle glycogen level and selected meat quality traits in beef," Meat Science, vol. 50, no. 3, pp. 389-393, 1998.

[58] A. Litwińczuk, M. Florek, P. Skałecki et al., "Chemical composition and physicochemical properties of horse meat from the longissimus lumborum and semitendinosus muscle," Journal of Muscle Foods, vol. 19, pp. 223-236, 2008.

[59] J. L. Aalhus, D. R. Best, A. C. Murray, and S. D. M. Jones, "A comparison of the quality characteristics of pale, soft and exudative beef and pork," Journal of Muscle Foods, vol. 9, no. 3, pp. 267-280, 1998.

[60] C. M. Jones, E. M. Hirschler, R. McKee, R. MartinezDawson, and A. R. Sams, "The characterization and incidence of pale, soft, exudative Turkey meat in a commercial plant," Poultry Science, vol. 79, no. 4, pp. 553-558, 2000.

[61] H. J. Swatland, "How $\mathrm{pH}$ causes paleness or darkness in chicken breast meat," Meat Science, vol. 80, no. 2, pp. 396400, 2008.

[62] S. J. Van Schalkwyk, S. Cloete, L. C. Hoffman et al., "The effect of pre-slaughter stress resulting from feed withdrawal on meat quality characteristics in ostriches," South African Journal of Animal Science, vol. 30, pp. 147-148, 2000.

[63] J. H. Choe, Y. M. Choi, S. H. Lee et al., "The relation between glycogen, lactate content and muscle fiber type composition, and their influence on postmortem glycolytic rate and pork quality," Meat Science, vol. 80, no. 2, pp. 355-362, 2008.

[64] C. E. Dreiling, D. E. Brown, L. Casale, and L. Kelly, "Muscle glycogen: comparison of iodine binding and enzyme digestion assays and application to meat samples," Meat Science, vol. 20, no. 3, pp. 167-177, 1987.

[65] T. M. Kelly and J. H. Exton, "A rapid method for the determination of glycogen content and radioactivity in small quantities of tissue or isolated hepatocytes," Analytical Biochemistry, vol. 71, no. 1, pp. 96-105, 1976.

[66] W. G. Yasmineh, J. I. Caspers, and A. Theologides, "Homogeneous trinder-coupled assay for the determination of glucose-6-phosphatase activity in tissue extracts," Clinical Biochemistry, vol. 25, no. 2, pp. 109-114, 1992.

[67] A. Apaoblaza, A. Galaz, P. Strobel, N. Ramírez-Reveco, and C. Gallo, "Glycolytic potential and activity of adenosine monophosphate kinase (AMPK), glycogen phosphorylase (GP) and glycogen debranching enzyme (GDE) in steer carcasses with normal $(<5.8)$ or high $(>5.9) 24 \mathrm{~h} \mathrm{pH}$ determined in M. longissimus dorsi," Meat Science, vol. 101, pp. 83-89, 2015.

[68] P. Henckel, A. Karlsson, M. T. Jensen et al., "Metabolic conditions in Porcine longissimus muscle immediately pre-slaughter and its influence on peri-and post mortem energy metabolism," Meat Science, vol. 62, pp. 145-155, 2002.

[69] J. V. Passonneau and O. H. Lowry, Enzymatic Analysis: a Practical Guide, Anonymous, Ed., Springer Science \& Business Media, New York, NY, USA, 1st edition, 1993.

[70] M. Aliani, L. J. Farmer, J. T. Kennedy et al., "Post-slaughter changes in ATP metabolites, reducing and phosphorylated sugars in chicken meat," Meat Science, vol. 94, pp. 55-62, 2013.

[71] N. Batlle, M. Aristoy, and F. Toldrá, "ATP metabolites during aging of exudative and nonexudative pork meats," Journal of Food Science, vol. 66, pp. 68-71, 2001.

[72] K. Ryu, N. D. Kim, S. I. Choi et al., "Identification of novel inhibitors of HCV RNA-dependent RNA polymerase by pharmacophore-based virtual screening and in vitro evaluation," Bioorganic \& Medicinal Chemistry, vol. 17, pp. 2975-2982, 2009.

[73] C. R. Calkins, T. R. Dutson, G. C. Smith et al., "Concentration of creatine phosphate, adenine nucleotides and their derivatives in electrically stimulated and nonstimulated beef muscle," Journal of Food Science, vol. 47, pp. 1350-1353, 1982.

[74] M. Kylä-Puhju, M. Ruusunen, and E. Puolanne, "Activity of porcine muscle glycogen debranching enzyme in relation to pH and temperature," Meat Science, vol. 69, pp. 143-149, 2005.

[75] E. M. England, S. K. Matarneh, T. L. Scheffler et al., "Altered AMP deaminase activity may extend postmortem glycolysis," Meat Science, vol. 102, pp. 8-14, 2015.

[76] M. Aliani and L. J. Farmer, "Precursors of chicken flavor. I. Determination of some flavor precursors in chicken muscle," Journal of Agricultural and Food Chemistry, vol. 53, pp. 6067-6072, 2005.

[77] P. Henckel, P. F. Jørgensen, and P. Jensen, "Glycogen content, buffering capacity and resting $\mathrm{pH}$ in live muscles of pigs of different halothane genotypes (a pilot project)," Meat Science, vol. 32, pp. 131-138, 1992.

[78] H. U. Bergmeyer, Methods of Enzymatic Analysis, Anonymous, Ed., Academic Press, New York, NY, USA, 2nd edition, 1974.

[79] R. Scheier, J. Köhler, and H. Schmidt, "Identification of the early postmortem metabolic state of porcine M. semimembranosus using Raman spectroscopy," Vibrational Spectroscopy, vol. 70, pp. 12-17, 2014.

[80] J. Damez and S. Clerjon, "Quantifying and predicting meat and meat products quality attributes using electromagnetic waves: an overview," Meat Science, vol. 95, pp. 879-896, 2013.

[81] G. ElMasry, D. Sun, and P. Allen, "Near-infrared hyperspectral imaging for predicting colour, $\mathrm{pH}$ and tenderness of fresh beef," Journal of Food Engineering, vol. 110, pp. 127$140,2012$.

[82] R. A. Lawrie and D. A. Ledward, Lawrie's Meat Science, Anonymous, Ed., Woodhead Publishing, Cambridge, UK, 7th edition, 2006.

[83] J. Damez and S. Clerjon, "Meat quality assessment using biophysical methods related to meat structure," Meat Science, vol. 80, pp. 132-149, 2008.

[84] H. J. Swatland, "Rigor and cold shortening," in Structure and Development of Meat Animals and Poultry, pp. 553-563, CRC Press, Boca Raton, FL, USA, 2019.

[85] E. Tornberg, M. Wahlgren, J. Brøndum et al., "Pre-rigor conditions in beef under varying temperature-andpH-falls studied with rigometer, NMR and NIR," Food Chemistry, vol. 69, pp. 407-18, 2000.

[86] C. E. Devine, N. M. Wahlgren, and E. Tornberg, "Effect of rigor temperature on muscle shortening and tenderisation of 
restrained and unrestrained beef $\mathrm{m}$. longissimus thoracicus et lumborum," Meat Science, vol. 51, pp. 61-72, 1999.

[87] C. Hertzman, U. Olsson, and E. Tornberg, "The influence of high temperature, type of muscle and electrical stimulation on the course of rigor, ageing and tenderness of beef muscles," Meat Science, vol. 35, pp. 119-141, 1993.

[88] C. E. Devine, M. A. Wahlgren, and E. Tornberg, "The effects of rigor temperature on shortening and meat tenderness," in Proceedings of the 42nd International Congress of Meat Science and Technology, pp. 396-397, Lillehammer, Norway, 1996.

[89] A. Vain, R. Kauppila, and E. Vuori, "Estimation of the breaking of rigor mortis by myotonometry," Forensic Science International, vol. 79, pp. 155-61, 1996.

[90] S. A. El Karam, P. Berge, and J. Culioli, Application of Ultrasonic Data to Classify Bovine Muscles, pp. 1197-1200, Toronto, Cánada, 1997.

[91] J. Ophir, R. K. Miller, H. Ponnekanti et al., "Elastography of beef muscle," Meat Science, vol. 36, pp. 239-50, 1994.

[92] C. Dwyer, P. Allen, and V. Buckin, "Temperature dependence of the ultrasonic parameters of bovine muscle: effects of muscle anisotropy," in Trends in Colloid and Interface Science XIV, pp. 282-286, Springer, Berlin, Germany, 2000.

[93] B. Park, A. D. Whittaker, R. K. Miller et al., "Predicting intramuscular fat in beef longissimus muscle from speed of sound," Journal of Animal Science, vol. 72, pp. 109-116, 1994.

[94] D. Mörlein, F. Rosner, S. Brand et al., "Non-destructive estimation of the intramuscular fat content of the longissimus muscle of pigs by means of spectral analysis of ultrasound echo signals," Meat Science, vol. 69, pp. 187-199, 2005.

[95] S. I. Mortimer, N. M. Fogarty, J. H. J. van der Werf et al., "Genetic correlations between meat quality traits and growth and carcass traits in Merino sheep," Journal of Animal Science, vol. 96, pp. 3582-3598, 2018.

[96] Z. Nogalski, P. Pogorzelska-Przybyłek, I. Białobrzewski et al., "Estimation of the intramuscular fat content of $\mathrm{m}$. longissimus thoracis in crossbred beef cattle based on live animal measurements," Meat Science, vol. 125, pp. 121-127, 2017.

[97] S. H. A. Raza, L. Gui, R. Khan et al., "Association between FASN gene polymorphisms ultrasound carcass traits and intramuscular fat in Qinchuan cattle," Gene, vol. 645, pp. 55-59, 2018.

[98] A. Ludwiczak, M. Stanisz, D. Lisiak et al., "Novel ultrasound approach for measuring marbling in pork," Meat Science, vol. 131, pp. 176-182, 2017.

[99] S. F. Eby, P. Song, S. Chen et al., "Validation of shear wave elastography in skeletal muscle," Journal of Biomechanics, vol. 46, pp. 2381-2387, 2013.

[100] A. Ayadi, J. Culioli, and S. Abouelkaram, "Sonoelasticity to monitor mechanical changes during rigor and ageing," Meat Science, vol. 76, pp. 321-326, 2007.

[101] S. E. Prussia, J. J. Astleford, and B. Hewlettet, NonDestructive Firmness Measuring Device, University of Georgia Research Foundation Inc (UGARF), EEUU, Patent number: US5372030A, 1994.

[102] Y. S. Lee, C. M. Owens, and J. F. Meullenet, "A novel laser air puff and shape profile method for predicting tenderness of broiler breast meat," Poultry Science, vol. 87, no. 7, pp. 1451-1457, 2008.

[103] G. S. Mittal, R. Nadulski, S. Barbut et al., "Textural profile analysis test conditions for meat products," Food Research International, vol. 25, pp. 411-417, 1992.

[104] W. M. Brenee, "Application of texture profile analysis to instrumental food texture evaluation," Journal of Texture Studies, vol. 6, pp. 53-82, 1975.
[105] F. R. De Huidobro, E. Miguel, B. Blázquez et al., "A comparison between two methods (Warner-Bratzler and texture profile analysis) for testing either raw meat or cooked meat," Meat Science, vol. 69, pp. 527-536, 2005.

[106] C. Li, P. Shi, C. Xu et al., "Tracing processes of rigor mortis and subsequent resolution of chicken breast muscle using a texture analyzer," Journal of Food Engineering, vol. 100, pp. 388-391, 2010.

[107] O. Vangen, K. Gronseth, A. Evensen et al., "Estimation of body composition in live animals by use of computerized tomography," Annales de Génétique et de Sélection Animale, vol. 14, pp. 123-124, 1982.

[108] N. Clelland, L. Bunger, K. A. McLean et al., "Prediction of intramuscular fat levels in Texel lamb loins using X-ray computed tomography scanning," Meat Science, vol. 98, pp. 263-271, 2014.

[109] J. Kongsro and E. Gjerlaug-Enger, "In vivo prediction of intramuscular fat in pigs using computed tomography," Open Journal of Animal Sciences, vol. 3, p. 321, 2013.

[110] C. Kröger, C. M. Bartle, J. G. West et al., "Meat tenderness evaluation using dual energy X-ray absorptiometry (DEXA)," Computers and Electronics in Agriculture, vol. 54, pp. 93-100, 2006

[111] C. Kroger, Evaluation of Meat Tenderness, Institute Of Geological And Nuclear Sciences Ltd., Patent number US2009310826, 2009.

[112] T. Osawa, K. Kuchida, S. Hidaka et al., "Genetic parameters for image analysis traits on M. longissimus thoracis and M. trapezius of carcass cross section in Japanese Black steers," Journal of Animal Science, vol. 86, pp. 40-46, 2008.

[113] H. Huang, L. Liu, M. O. Ngadi et al., "Prediction of pork marbling scores using pattern analysis techniques," Food Control, vol. 31, pp. 224-229, 2013.

[114] H. J. Swatland, On-Line Monitoring of Meat Quality, Anonymous, Ed., CRC Press, Woodhead Publisher, Cambridge, UK, 2002.

[115] R. Rødbotten, B. N. Nilsen, and K. I. Hildrum, "Prediction of beef quality attributes from early post mortem near infrared reflectance spectra," Food Chemistry, vol. 69, pp. 427-436, 2000.

[116] A. H. Hoving-Bolink, H. W. Vedder, J. W. M. Merks et al., "Perspective of NIRS measurements early post mortem for prediction of pork quality," Meat Science, vol. 69, pp. 417423, 2005.

[117] M. M. Reis and K. Rosenvold, "Early on-line classification of beef carcasses based on ultimate $\mathrm{pH}$ by near infrared spectroscopy," Meat Science, vol. 96, pp. 862-869, 2014.

[118] G. K. Naganathan, K. Cluff, A. Samal et al., "Three dimensional chemometric analyses of hyperspectral images for beef tenderness forecasting," Journal of Food Engineering, vol. 169, pp. 309-320, 2016

[119] M. Kamruzzaman, G. ElMasry, D. Sun et al., "Prediction of some quality attributes of lamb meat using near-infrared hyperspectral imaging and multivariate analysis," Analytica Chimica Acta, vol. 714, pp. 57-67, 2012.

[120] D. F. Barbin, G. ElMasry, D. Sun et al., "Predicting quality and sensory attributes of pork using near-infrared hyperspectral imaging," Analytica Chimica Acta, vol. 719, pp. 30-42, 2012.

[121] Z. Xiong, D. Sun, X. Zeng et al., "Recent developments of hyperspectral imaging systems and their applications in detecting quality attributes of red meats: a review," Journal of Food Engineering, vol. 132, pp. 1-13, 2014. 


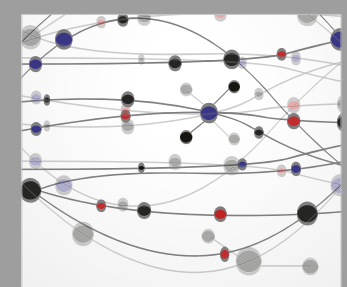

The Scientific World Journal
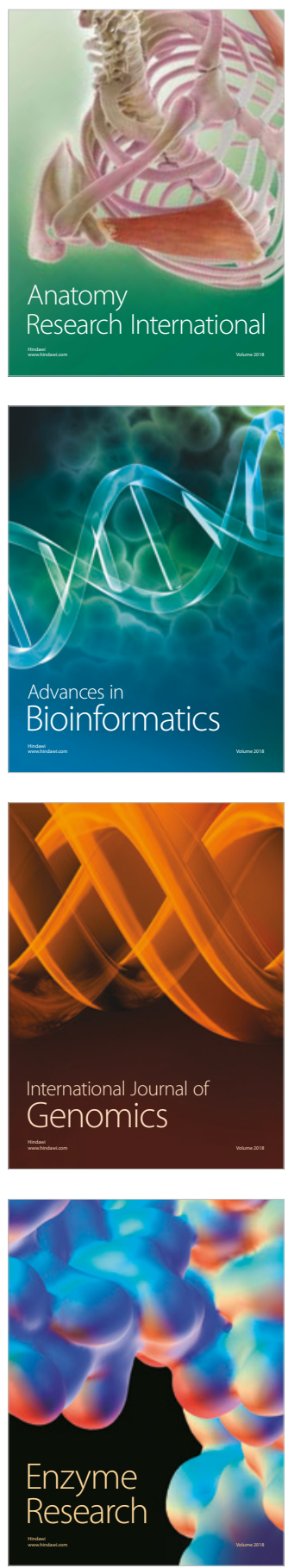
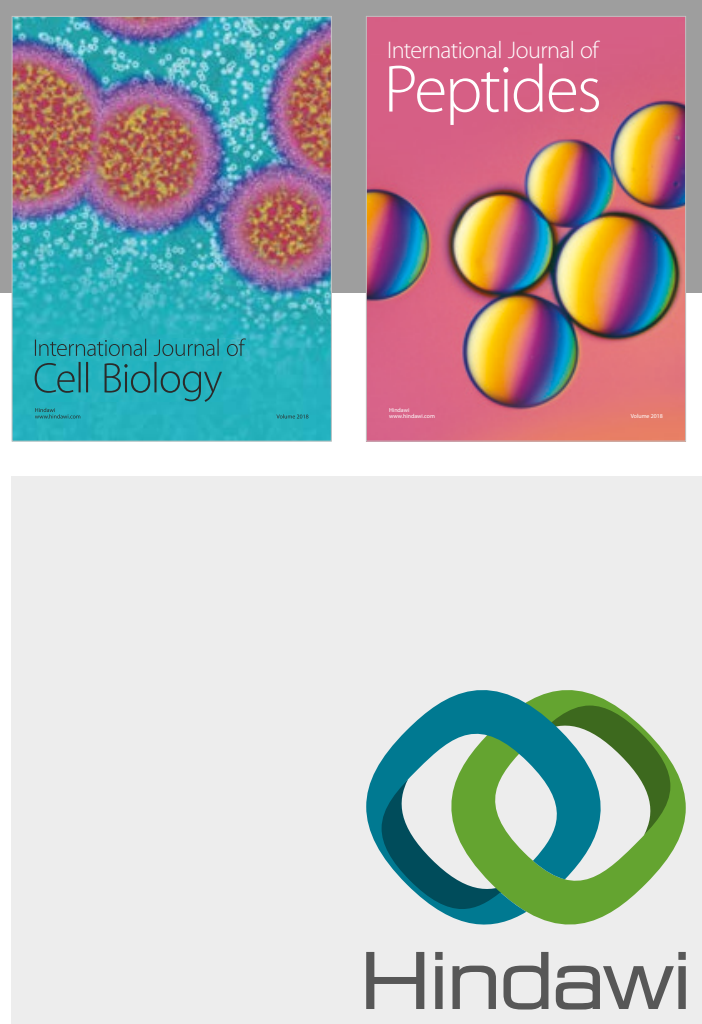

Submit your manuscripts at

www.hindawi.com
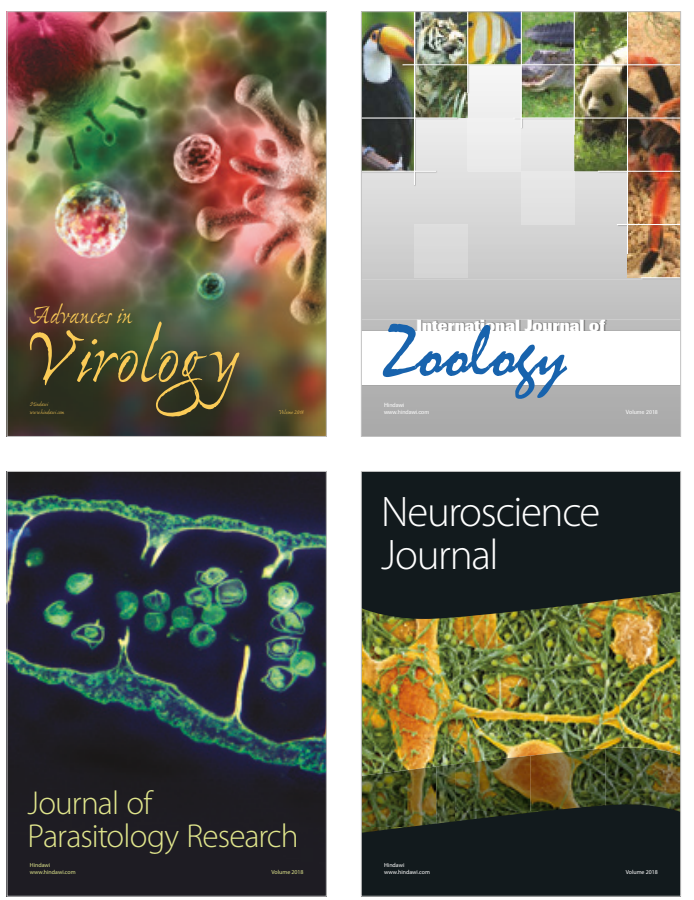
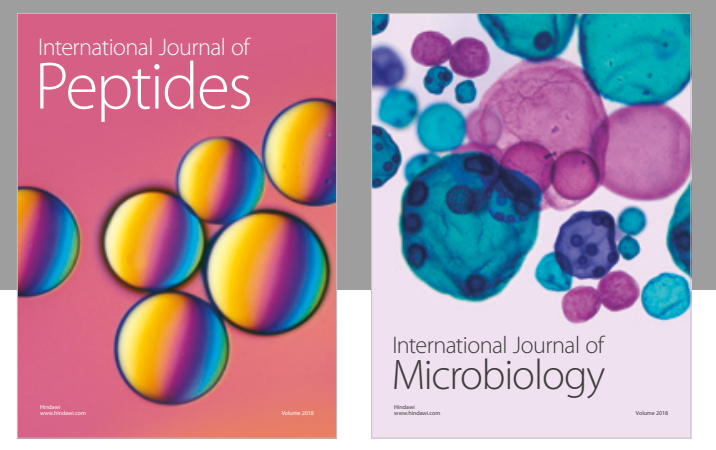

nternational Journal of Microbiology
Journal of
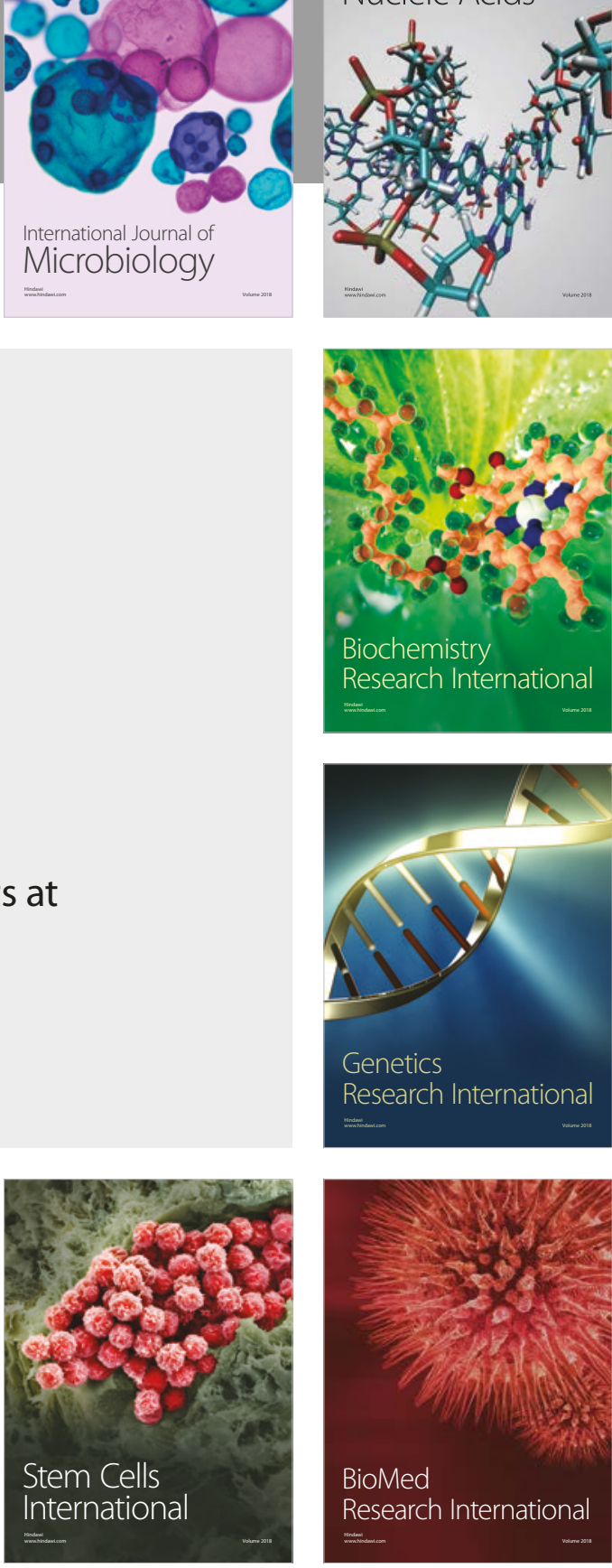
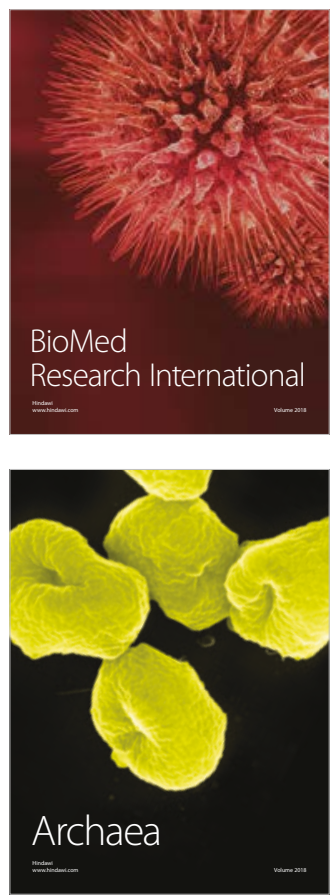